\title{
Seroprevalence of Herpes Simplex Virus Type 2 and HIV Co-Infection Among Pregnant Women in Jigawa State
}

\author{
Amoo Florence Kemi*, Sani Nura Muhammad, Gumel Ahmad Muhammad, Eze Lovelyn Chinyere, \\ Nafisat Baita, Mukhtar Sa'adatu Ismail, Dauda Hauwa Sani
}

Department of Microbiology and Biotechnology, Faculty of Science, Federal University, Dutse, Nigeria

Email address:

amooflorence@gmail.com (A. F. Kemi)

${ }^{*}$ Corresponding author

To cite this article:

Amoo Florence Kemi, Sani Nura Muhammad, Gumel Ahmad Muhammad, Eze Lovelyn Chinyere, Nafisat Baita, Mukhtar Sa'adatu Ismail, Dauda Hauwa Sani. Seroprevalence of Herpes Simplex Virus Type 2 and HIV Co-Infection Among Pregnant Women in Jigawa State. International Journal of Microbiology and Biotechnology. Vol. 5, No. 1, 2020, pp. 1-6. doi: 10.11648/j.ijmb.20200501.11

Received: December 11, 2019; Accepted: December 25, 2019; Published: January 8, 2020

\begin{abstract}
Herpes simplex virus type 2 (HSV-2) infections is one of the most common sexually transmitted infections Worldwide. It facilitates the acquisition of HIV and is the primary cause of genital herpes which when acquired by women during pregnancy account for half of the mobidity and mortality among neonates. Lifelong latent HSV-2 infection raises concern among women of reproductive age considering the risk of neonatal transmission. In Nigeria screening for HSV-2 and co-infection with HIV in antenatal clinics is not routinely done. A cross-sectional study, was carried out among pregnant women attending antenatal clinics in four hospitals in Jigawa state. A total of 300 consenting pregnant women were enrolled, the study involved collection of sociodemographic data and laboratory determination of HSV-2 immunoglobulin G (IgG) and HIV seroprevalence using WHO standard procedure of Enzyme Linked Immunosorbent Assay (ELISA) test kit (DIAPRO Diagnostic Bioprobes, Milano, Italy), UNI-GOLD Wicklow, Ireland and ALERE Determine, respectively. Statistical significance was determined at $\mathrm{p}<0.05 \mathrm{Of}$ the 300 samples tested, overall seroprevalence of $55(18.3 \%)$ and $44(14.7 \%)$ for HSV-2 and HIV were recorded. The HSV-2 and HIV Co-infection rate was $16(5.3 \%)$ among respondent. About $87.5 \%$ of the co-infection occurred in respondents that were in their $2^{\text {nd }}$ Trimester. Addionally, co-infection was found to be high among respondents between the age of $15-34$ yrs with $81.3 \%$. In this study, education status, parity, stage of pregnancy, occupation, History of blood transfusion had no statistical significance with HSV-2 and HIV co-infection ( $>0.05$ ). This study has demonstrated the existence and risk of neonatal herpes in the study area. It is recommended that HSV testing should be placed among the standard medical checkup tests in the area, again advocacy and public awareness on the potential public health burden of HSV-2 and HIV co-infection should be observed.
\end{abstract}

Keywords: HIV, HSV-2, Virus, Co-infection, ELISA, STIs, Neonatal

\section{Introduction}

Herpes Simplex virus type 2 (HSV-2) is one of the most common sexually transmitted infection worldwide, HSV-2 is the predominant cause of genital herpes, although it leads to periodic recurrences of painful genital ulcers in symptomatic individuals; it is asymptomatic in about $80 \%-90 \%$ of individuals in whom viral reactivation and shedding occur undetected [1]. Hence, HSV-2 transmissions can remain sustainable in the general public and the prevalence rates can reach very high levels if interventions to curb the infection are not taken.

There is a direct relationship between HSV-2 and HIV prevalence, and both viruses have reciprocal biological interactions [2]. Due to ulcerative lesions caused by HSV-2 progression, it has been associated with the risk of HIV acquisition and HIV transmission. Furthermore, in HIVpositive patients, infection with HSV-2 accelerates replication and genital shedding of the virus; thus, such individuals are more likely to transmit HIV [3]. In fact, HSV2 is the primary cause of genital ulcers, among potentials cofactor of HIV herpes viruses are commonly mentioned because they are ubiquitous and contagious. It has been 
reported that, among HIV positive patient's co-infection with HSV-2 stands at 30\%-70\% in Europe and 50\%-90\% was recorded for Africa [4].

HSV-2 and HIV are two lifelong viral sexually transmitted infections (STIs) of global health importance. HSV-2 and HIV co-infection among pregnant women may increase the risk of perinatal transmission of HIV [3]. Genital lesions due to herpes are often very painful, and can lead to substantial psychological morbidity, the virus can also be passed from mother to child during birth which can be very serious, without treatment $80 \%$ of infants with disseminated disease die and those who do survive often have brain damage. Herpes simplex virus and HIV may also adversely affect the outcome of pregnancy, leading to spontaneous Abortion, premature delivery and low birth weight infants [5]. Coinfection with HSV-2 and HIV among pregnant women may increase the risk of maternal-to-fetal transmission of HIV by as much as $25 \%$ [6].

Herpes simplex type-2 virus infection in pregnancy often manifests clinically in a manner similar to that in a nonpregnant female and are commonly asymptomatic except in few cases of disseminated disease [7]. Genital herpes among pregnant women is associated with definite risk for neonatal meningoencephalitis [8]. And mortality from neonatal herpes is well above $50 \%$ even in developed countries [1]. Regardless of antiviral therapy, neonatal meningoencephalitis kills about $50 \%$ of affected babies and leaves the survivors with permanent neurological deficit, while disseminated neonatal disease kills nearly $90 \%$ of the infected infants [8]. Early detection and treatment of HSV-2 during pregnancy are invaluable in limiting the risk of vertical transmission of HSV-2 to the fetus/newborn as well as disseminated maternal disease. For women with primary HSV-2 presenting with genital ulceration at the time of labor, the risk of transmission can be reduced via cesarean section [1]. Furthermore, pregnant women infected with genital herpes can transmit the virus to the foetus, which can lead to serious neonatal complications, such as neurologic problems, brain damage and even death [9]. Study in the United States of America (USA) shows that four of nine infants born to women who acquired genital herpes shortly before labour developed neonatal infection of which one died [10]. While some studies report poor outcome in reduction of HIV acquisition and transmission via the use of antivirals for treatment of HSV-2, it has been suggested that high-dose antivirals may reduce HIV viral load in HSV-2/HIV co-infected patients [11]. However, it is clear that strategies to curb the HIV pandemic via the intervention measures for HSV infection control continue to be evaluated. HSV infection is said to be a significant factor because it increases the risk of the acquisition and transmission of HIV, in pregnant women it enhances the mother to child transmission (MTCT) of HIV. The reciprocal enhancement of HSV and HIV viral replication in the presence of concurrent infection has also been described by several researchers [12]. This study aims to determine the seroprevalence of HSV-2 and HIV coinfection among pregnant women in Jigawa state and identify the risk factors involved in the progression of the infection. To the best of our knowledge this is the first report of HSV-2 seroprevalence and HIV co-infection in Jigawa State of Nigeria. It is hope that the study will serve as a highlight for policy makers to take informed decision on HSV-2 and HIV management strategies.

\section{Materials and Methods}

\subsection{Study Area}

The study was conducted in four Hospitals of the three senatorial districts of Jigawa State. Jigawa is located in North West geographical zone between Latitudes $11^{\circ} \mathrm{E} 13^{\circ} \mathrm{N}$ and Longitudes $8^{\circ} \mathrm{E} 13^{\circ} \mathrm{E}$. The samples were collected from Rasheed Shekoni Teaching Hospital, Dutse General Hospital, Gumel General Hospital and Hadejia General Hospital, Jigawa, the four hospitals have high rate of client load and they are general government hospitals also a referral center.

\subsection{Study Population}

The study population comprises of 300 pregnant women selected at random from each hospital in the geopolitical zones. The participant used were enlisted after they granted their full consent to participate in the study.

\subsection{Inclusion Criteria}

Only pregnant women attending antenatal clinics in General Hospital Gumel, General Hospital Hadejia, Dutse General Hospital and Rasheed Shekoni Specialist Hospital Dutse, Jigawa State, Nigeria who agreed to participate in the study were included.

\subsubsection{Exclusion Criteria}

All pregnant women attending antenatal clinics in the three hospitals that declined to give consent for inclusion were excluded from the study.

\subsubsection{Informed Consent}

Informed written consent was obtained from all the experimental population before inclusion using approved protocol.

\subsection{Ethical Clearance}

Ethical clearance for the study was obtained from Ministry of Health Dutse, Jigawa state. Before conducting the study.

\subsection{Sample Collection and Sample Size}

Samples were collected from Rasheed Shekoni Teaching Hospital, Dutse General Hospital, Gumel General Hospital and Hadejia General Hospital, of Jigawa State. The four hospitals have high rate of client load and they are all public hospitals and each among them serve as referral center.

A random sampling technique was used to obtain the study sample size in which all pregnant women that suit the set inclusion criteria were recruited for the study. The sample 
size was determined using Reed-Frost model $N=\frac{Z^{2} P q}{d^{2}}$ as reported previously by [13].

\subsubsection{Data and Blood Sample Collection}

A structured closed ended questionnaire designed for the study was used to obtain data on demographic and social status of the participants. Venous blood $(5 \mathrm{ml})$ was drawn aseptically by venipuncture into vacutainer tubes. Separation of the serum was performed by centrifugation of the blood samples at 1,600 revolutions per minutes (rpm) for 5 minutes using bench top centrifuge. Serum samples were collected into freshly labelled Cyro tubes and stored at $4{ }^{\circ} \mathrm{C}$ in a cool box with ices blocks and transported to the Microbiology Laboratory, FUD for ELISA analysis.

\subsubsection{Sample Analysis}

All samples were screened using qualitative sandwich third- generation Diapro HSV-2 specific enzyme-linked immunosorbent assay (ELISA) kit that is type specific IgG against the glycoprotein G of HSV-2 (DIAPRO Diagnostic Bio probes, Milano, Italy). The samples were screened for HIV antibody according WHO standard procedure of using rapid immunoassay kit (Alere Determine ${ }^{\circledR}$ HIV1\&2 Chiba, Japan); thereafter, all positive samples were retested with another immunoassay kit (Trinity Biotech Uni-Gold ${ }^{\mathrm{TM}} \mathrm{HIV}$,
Wicklow, Ireland) and Stat pack kits according to manufacturer's guideline.

\subsection{Statistical Analysis}

Statistical analyses were observed using SPSS version 20 (IBM, USA). Pearson's Chi square test was performed at $95 \%$ confidence interval, and all statistical significance were established at $\mathrm{p}<0.05$.

\section{Result}

A total of 300 pregnant women were recruited in this study. Tables 1 and 2 showed the prevalence of HSV-2 co-infections and non-co-infections with HIV among respondent. The analysis indicated that a total number of $16(5.3 \%)$ were under co-infections of HIV and HSV-2 while the remaining $284(94.7 \%)$ of the respondents were under non-co-infections of HIV and HSV-2. Risk factors associated with HSV-2 infection were also studied, and the result is given in Table 3. Table 4: showed significantly $(P<0.05)$ higher percentage of HSV-2 infection among pregnant women reactive for HIV infection. (36.4\%) of HIV positive pregnant women are also reactive for HSV-2 infection but with just (15.2\%) of HIV non-reactive pregnant women being HSV-2 cases.

Table 1. Seroprevalence of HSV-2 and HIV Co-Infection disaggregated by demographic characteristics.

\begin{tabular}{|c|c|c|c|c|}
\hline Variable & Frequency (\%) & Frequency (\%) & $\chi^{2}$ & (p Value) \\
\hline Co-Infection $(n=16)$ & & Non-Co-Infection $(\mathrm{n}=284)$ & & \\
\hline Age Group & & & 1.181 & $(0.404)$ \\
\hline $15-24$ & $5(31.3 \%)$ & $117(41.2 \%)$ & & \\
\hline $25-34$ & $8(50.0 \%)$ & $141(49.6 \%)$ & & \\
\hline $35-44$ & $3(18.7 \%)$ & $26(9.2 \%)$ & & \\
\hline Educational Status & & & 4.586 & $(0.204)$ \\
\hline Primary & $3(18.8 \%)$ & $111(39.1 \%)$ & & \\
\hline Secondary & $3(18.8 \%)$ & $36(12.7 \%)$ & & \\
\hline Tertiary & $0(0.0 \%)$ & $18(6.3 \%)$ & & \\
\hline Trimester & & & 1.043 & $(0.593)$ \\
\hline First & $0(0.0 \%)$ & $11(3.9 \%)$ & & \\
\hline Second & $14(87.5 \%)$ & $222(78.1 \%)$ & & \\
\hline Third & $2(12.5 \%)$ & $51(18.0 \%)$ & & \\
\hline None & $1(6.3 \%)$ & $7(2.5 \%)$ & & \\
\hline One & $2(12.5 \%)$ & $47(16.5 \%)$ & & \\
\hline Two & $7(43.7 \%)$ & $147(51.8 \%)$ & & \\
\hline Three & $3(18.8 \%)$ & $39(13.7 \%)$ & & \\
\hline Four & $2(12.5 \%)$ & $34(11.9 \%)$ & & \\
\hline Five & $1(6.3 \%)$ & $10(3.5 \%)$ & & \\
\hline Occupation & & & 1.608 & $(0.657)$ \\
\hline Civil servant & $0(0.0 \%)$ & $17(6.0 \%)$ & & \\
\hline House wives & $11(68.7 \%)$ & $167(58.8 \%)$ & & \\
\hline Trader & $4(25.0 \%)$ & $67(25.6 \%)$ & & \\
\hline Others & $1(6.3 \%)$ & $33(11.6 \%)$ & & \\
\hline Type of Marriage & & & 0.267 & $(0.605)$ \\
\hline Monogamy & $11(68.7 \%)$ & $177(62.3 \%)$ & & \\
\hline
\end{tabular}


Table 2. Seroprevalence of HIV among pregnant women in some selected hospital Jigawa State, with respect to some demographic variables.

\begin{tabular}{|c|c|c|c|c|}
\hline Variable & Frequency (\%) & Frequency (\%) & $X^{2}$ & (P Value) \\
\hline No. Examined & & No. Positive & & \\
\hline History of blood transfusion & & $13(29.5 \%)$ & 2.633 & $(0.105)$ \\
\hline Yes & $57(19.0 \%)$ & $31(70.5 \%)$ & & \\
\hline No & $243(81.0 \%)$ & & & \\
\hline Syphilis & & & 5.762 & $(0.016) *$ \\
\hline Reactive & $101(33.7 \%)$ & $23(52.3 \%)$ & & \\
\hline Non-Reactive & $199(66.3 \%)$ & $21(47.7 \%)$ & & \\
\hline \multicolumn{5}{|l|}{ Knowledge on HSV-2 } \\
\hline Yes & $2(0.7 \%)$ & $6(13.6 \%)$ & \multirow{2}{*}{8.416} & \multirow{2}{*}{$(0.000) *$} \\
\hline No & $298(99.3 \%)$ & $38(86.4 \%)$ & & \\
\hline
\end{tabular}

KEY: * indicate level of significant of $\mathrm{p}<0.05$.

Table 3. Risk Factors for Herpes Simplex Type 2 Virus and Huma Immunodeficiency Virus Co-Infection in Respondents.

\begin{tabular}{|c|c|c|c|}
\hline \multirow{2}{*}{ Risk Factors } & Co-Infection $(\mathrm{N}=16)$ & Non-Infection $(\mathrm{N}=284)$ & \multirow{2}{*}{$\chi^{2}$ (p Value) } \\
\hline & Frequency (\%) & Frequency (\%) & \\
\hline History of STIs & & & $7.868(0.005) *$ \\
\hline YES & $11(68.8 \%)$ & $97(34.2 \%)$ & \\
\hline $\mathrm{NO}$ & $5(31.2 \%)$ & $187(65.8 \%)$ & \\
\hline Syphilis & & & $12.930(0.000) *$ \\
\hline REACTIVE & $12(75.0 \%)$ & $89(31.3 \%)$ & \\
\hline NON-REACTIVE & $4(25.0 \%)$ & $195(68.7 \%)$ & \\
\hline Infected Partner & & & $9.419(0.009) *$ \\
\hline YES & $2(12.5 \%)$ & $8(2.8 \%)$ & \\
\hline NO & $0(0 \%)$ & $79(27.8 \%)$ & \\
\hline DON'T KNOW & $14(87.5 \%)$ & $197(69 \%)$ & \\
\hline
\end{tabular}

KEY: * indicate level of significant of $\mathrm{p}<0.05$.

Table 4. Frequency of infections with HSV-2 in pregnant women positive with HIV.

\begin{tabular}{llllll}
\hline HIV & & HSV-2 & & Total & p Value \\
\cline { 3 - 6 } & & Reactive & Non-Reactive & 44 & 0.001 \\
Reactive & Count & 16 & 28 & $100.0 \%$ & \\
& \% within HIV & $36.4 \%$ & $63.6 \%$ & 256 & \\
\multirow{2}{*}{ Non-Reactive } & Count & 39 & 217 & $100.0 \%$ & 300 \\
\multirow{2}{*}{ Total } & \% within HIV & $15.2 \%$ & $24.8 \%$ & 300 & \\
\hline
\end{tabular}

C. $\mathrm{L} .=1.58-6.42$, O. R. $=3.18, \chi^{2}=11.196$.

Key: - C. I. $=$ Confidence interval, O. R. $=$ Odds Ratio, $P<0.05$ is taken for significant disease co-infection.

\section{Discussion}

Genital herpes is one of the most common sexually transmitted infections among women of reproductive age; it can be contracted and transmitted to the fetus during pregnancy and the new born. Herpes simplex virus infection is a global public health problem; it can cause significant distress and have devastating impact on the social and psychological wellness of an individual [14]. Pregnant women with genital herpes caused by HSV-2 can transmit the virus to their neonate at birth, the greatest risk of transmission to the fetus and newborn occurs in cases of initial maternal infection contracted in the second half of pregnancy, which is a potential cause of neonatal mortality and morbidity [15].

The overall seroprevalence of $18.3 \% \mathrm{HSV}-2$ infection was recorded in this study which is lower than the $35.5 \%$ reported in a similar study among pregnant women attending F. M. C., Keffi, Nigeria by [16] and $33.3 \%$ among pregnant women in Ibadan in Nigeria [17]. But agrees with $7.5 \%$ and $21 \%$ reported among pregnant women in India and USA, respectively [18].

HIV Seroprevalence rate of $14.7 \%$ was recorded in this study, this is relatively high when compare to $2.4 \%$ rate found among pregnant women in Lokoja, North central reported by [19].

The percentage of respondents who were co-infected with HSV-2 and HIV was found to be $5.3 \%$ which is related to the co-infection rate of $2.8 \%$ and $2.4 \%$ reported by $[12,19]$ respectively; but lower than that of $[16,20]$. The co-infection rate of $5.3 \%$ obtained from this study is quite low when compared with $38.8 \%$ found among pregnant women in Ibadan, Nigeria [17] and $44.6 \%$ reported by [21] among 
patent attending sexually transmitted infections clinics in Ibadan. The relatively low prevalence of HSV-2 and HIV coinfection in this study can be attributed to the differences in the study population between previous studies and this present one, while their study population was among commercial sex workers and STI clinic attendees. Coinfection occurs most in those between 15-34yrs with $(81.3 \%)$, while those in 35-45yrs (18.7\%). Similar observations were reported by earlier works those young middle-aged subjects are more sexually active which makes them more vulnerable [8]. Co-infection is high among women without any formal education (62.5\%) and least among women with primary and secondary education (18. $8 \%$ ), which could result from lack of enlightenment and awareness of the disease. It was observed that there is no association between parity and co-infection among respondents with $\left(\mathrm{p}=0.918\right.$ and $\left.\chi^{2}=1.453\right)$.

With reference to occupation house wives recorded highest prevalence of $(68.8 \%)$, follow by Traders $(25 \%)$, others $(6.2 \%)$ and no record of it was found among civil servants, it could be due to lack of awareness of the disease. This however does not indicate a statistically significant with $\mathrm{P}>0.05$. There was no significant association between stage of pregnancy and co-infection $\left(\mathrm{p}=0.593\right.$ and $\left.\chi^{2}=1.042\right)$, the prevalence was high among pregnant women in their second trimester $(87.5 \%)$ and least among pregnant women in third trimester $(12.5 \%)$, no record of co-infection was found among respondent in their first trimester, this report is in consonance with $47 \%$ and $65.2 \%$ findings of $[16,20]$ respectively.

History of blood transfusion among respondent was not found to be associated with the co-infection ( $\mathrm{p}=0.529$ and $\chi^{2}=0.395$ ), the viral co-infection was high among those who had no history of blood transfusion (75\%) than those with history of blood transfusion (25\%). Knowledge of HSV-2 has statistically significant with $\left(\mathrm{p}=0.005\right.$ and $\left.\chi^{2}=7.956\right)$, the co infection was high among women who had no knowledge of the viral infection with $(93.7 \%)$ than those with the knowledge $(6.3 \%)$, which is similar to report by [22]. This may result from lack of awareness of the diseases.

With reference to history of STIs, women with history of STIs recorded high prevalence $(68.8 \%)$ than those without history $(31.2 \%)$. However, there is statistical significance of ( $p=0.005$ and $\chi^{2}=7.868$ ), which agrees with previous studies of $[16,23]$. Co-infection rate with Syphilis was found to be high with $(75 \%)$ as compared to those that are non-reactive $(25 \%)$. The relation between Syphilis and co-infection rate was significant with $\left(\mathrm{p}=0.000\right.$ and $\left.\chi^{2}=12.930\right)$. This agrees with findings of [24] that Genital ulcers from HSV-2 and Syphilis are associated with HIV acquisition.

In this study, it was observed that most of the respondent with HIV infection also had HSV-2, 36.4\% of HIV positive pregnant women are also positive for HSV-2 infection while just $15.2 \%$ of HIV negative respondents are positive for HSV-2, it was statistically significant with $p=0$. 001. The odds ratio of being at risk of contracting HSV-2 infection was 3.2 times higher for HIV positive pregnant women than those that are HIV negative. This is similar with the findings of $[19,25]$. that the presence of HSV-2 infection plays a critical role in the acquisition of the HIV infection. The mutual re-enforcement of transmission efficiency exhibited by HIV and HSV-2 infection could be contributory to high prevalence level of HSV-2 in some part of Nigeria, the increase shedding of HIV through genital herpes leisons and the fact that individual with $\mathrm{HSV}-2$ remain potentially infection make important contribution to HIV transmission in African. [1].

This study adds to the scarce information available concerning HSV-2 and HIV Co-infection rates among the pregnant population. However, it is limited to a sample of pregnant women attending the four selected hospitals in the three Senatorial districts in Jigawa State which is not representative of all pregnant women in Nigeria.

\section{Conclusion}

In this research, association between HSV-2 and HIV coinfection was studied among pregnant women. The rate of HSV-2 and HIV co-infection among the pregnant women in Jigawa State was found to be $16(5.3 \%)$, the factors that were found to be significantly associated with the occurrence were history of STIs, knowledge on HSV-2 infection and HIV status. Respondent with HSV-2 were 55 (18.3\%) and HIV were $44(14.7 \%)$. Hence it is necessary to routinely screen pregnant women for the possibility of HSV-2 infection to decrease neonatal herpes also control measures for HSV-2 and HIV infection is a logical approach as the synergistic effect of both viruses implies that the control of HSV-2 can be effective method of HIV prevention, thus bringing down the HIV pandemic to a low-level endemicity. These findings therefore indicate that health education, personal hygiene and screening interventions are highly required in an effort to prevent transmission to offspring which will help in reducing the risk of the infection among pregnant women in the area.

\section{Acknowledgements}

The authors wish to acknowledge the contributions of management and staff of Jigawa State Ministry of health as well as HIV infected pregnant women attending Rasheed Shekoni, Hadejia, Gumel and Dutse general hospitals, Jigawa State. Nigeria for their support and cooperation towards the success of this research.

\section{References}

[1] Corley, L. (2009). Synergistic co pathogens: HIV and HSV-2. $\begin{array}{lllll}\text { N. Engl J. } & \text { Med. 356: } & \text { 854-856. } \\ \text { https://dx.doi.org/10.1056/nejm199708213370801. } & \end{array}$

[2] Freeman, E., Weiss, H., Glynn, J., Cross, P. L., Withworth, J. A. and Hayes, R. J. (2006). Herpes simplex virus 2 infection increases HIV acquisition in men and women: Systematic review and meta-analysis of longitudinal studies, AIDS, 20: 73-83. 
[3] Bastien, S., Mason-Jones, A., De Koker, P., Mmbaga, E., Ross, D. and Mathews, C. (2016): Herpes simplex virus type-2 infection as a biomarker for sexual debut among young people in sub-Saharan Africa: a literature review. International journal STD AIDS. 23 (11): 761-766. https://www.ncbi.nlm.nih.gov/pubmed/23155093.

[4] Kalu, E. I. (2014). Seroprevalence of Herpes simplex virus infection among pregnant Women in Benin. International journal of Tropical Diseases and Health, 4 (1) 70-81. https://www.sciencedomain.org.

[5] Iche, K. E. (2014). Seroprevalence of herpes simplex virus infection among pregnant women attending Antenatal clinic in Benin, Nigeria. Int. J. Trop Dis Health. 4 (1): 70-81.

[6] Cowan, F. M, Humphrey J. H, Ntozini, R., Mutasa, K., Morrow, R. and Iliff, P., (2015): Maternal herpes simplex virus type 2 infection, syphilis and risk of intra-partum transmission ofHIV-1: Results of a case control study. AIDS. 22: 193-201.

[7] Chen, K. T., Segú, M., Lumey, L. H., Kuhn, L., Carter, R. J. and Bulterys, M. (2015): Genitalherpes simplex virus infection and perinatal transmission of human immunodeficiency virus. Obstet Gynecol. 106: 1341-8.

[8] Looker, K. J., Magaret, A. S., Turner, K. M. and Newman, L. M. (2015): Global estimate of prevalent and incident herpes simplex virus type 2 infections. PLoS One 2013; 10: e114989.

[9] Brown, Z. (2008). Preventing Herpes Simplex Virus Transmission to the Neonate. J. Infectious Disease 3; 175-186. https://dx.doi.org/10.1056/nejm.

[10] Brown, Z. A., Wald, A., Morrow, R. A., Selke, S., Zeh, J. and Corey L. (2003). Effect of serologic status and cesarean delivery on transmission rates of herpes simplex virus from mother to infant. JAMA. 289 (2): 203- 209: https://reference.Medscape.com/medline.

[11] Obijimi, O. T., Ajetomobi, A. B., Sule, W. P. and Olarewaju, D. O. (2013). Prevalence of herpes Simplex virus specific immunoglobulim-g and $-\mathrm{m}$ in pregnant women. South western Nigeria. Afr J clin Exp; 14: 134-139.

[12] Mawak, J. D., Dashe, N., Agabi, Y. A. and Zakeri, H. (2012). Seroprevalence and co-infection of herpes simplex virus type2 and human immunodeficiency virus in Nigeria Shiraz E-Med J. 13 (1): 12-44.

[13] Yusuf, M., Bolaji, N. and Herry, I. (2012). Prevalence of Herpes Simplex Virus among women in Nigeria. Journal of Virology, 80 (20), 9340-9348.
[14] Nabi, S. N., Wasey, A., Haider, K. M., and Hoque, M. M. (2012). Seroprevalence of TORCH Antibody in pregnant women. J. A. F. M. C. 8: 35-39.

[15] Idress, H. A. and Eihag, W. I. (2015). Seroprevalence of HSV2 among pregnant women Attending Malik Teaching Hospital, Khartoum State, Sudan. American J. 3: (11) 149-160.

[16] Otti, V. B., Usman, B. A., Pennap, G. R. and Eno-ibanga, C. K. (2017). Seroprevalence of Herpes simplex virus type-2 among pregnant women Accessing Antenatal care at Federal Medical Center, Keffi, Nigeria. Asian J. R. $M \&$ \&.$S .1$ (4): 1 6.

[17] Anaedobe, C. G. and Ajani, T. A. (2019). Co-infection of herpes simplex virus type-2 and HIV Infections among pregnant women in Ibadan, Nigeria. Global Infectious Disease; 11: 19-24. http://www.jgid.org/text.asp 2019/11/1/19/251843.

[18] Weiss, H. (2004). Epidemiolog1y of herpes simplex virus type -2 infection in the Developing World. Herpes 11: 24A-35A.

[19] Kolawole, O. M., Amuda, O. O., Suleiman, M. M., Nzurumike, C. and Ogah, J. I. (2016). Seroprevalence and Coinfection of HIV and HSV among pregnant women in Lokoja, North-Central Nigeria. Iranian RCM J. 18 (10): e25284.

[20] Amah, O. A., Bajaj, H. K., Singla, A. and Masih, H. (2015). Prevalence of HSV in pregnant Women from Gangetic, India. Advance Microbiology. 5: 404-408.

[21] Kolawole, O. M., Adu F. D., Agbede O. O. and Bakare R. A. (2008). Epidemiological patterns of HIV and HSV Coinfection in Ibadan, Nigeria. African Journal of Biomedical Research. 11: 23-26.

[22] Ameh, E. R., Aminu, M. and Ella, E. E. (2016). Seroprevalence of HSV-2 among women of Reproductive Age in Zaria, Kaduna State, Nigeria. Biology Medicals 8: 338.

[23] Celum, C., Levine, R., Weaver, M. and Wald, A. (2004). Genital herpes and human immunodeficiency virus: double trouble. Bull World Health Organ. 82 (6): 447-453. https://www.ncbi.nlm.nih.gov/pmc/articles/pmc2622854.

[24] Suazo, P. A., Tognarelli, E. I., Kalergis, A. M. and González, P. A. (2015). Herpes simplex virus 2 infection: molecular association with HIV and novel microbicides to prevent disease. Medical Microbiological Immunology. 204 (2): 161176. https://dx.doi.org./10.10077.

[25] Chun, H. M., Carpenter R. J. and Macalino G. E. (2013). The Role of Sexually transmitted infections in HIV-1 progression: Review of the Literature Disease: 176459. 